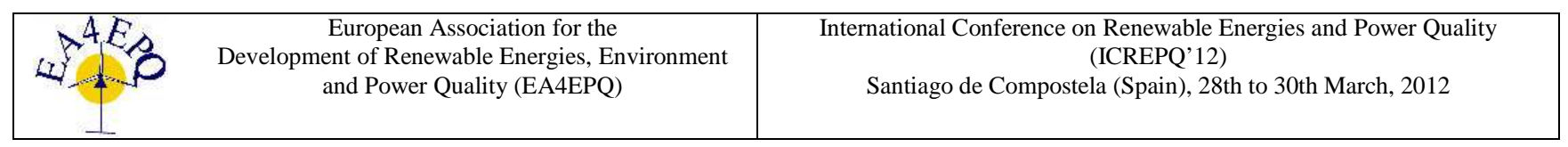

\title{
Performance Analysis of Methods at Estimating Insulated Cables Degradation
}

\author{
L. N. Velasco ${ }^{1}$, A. Reis ${ }^{1}$, J. C. Oliveira ${ }^{1}$, L. C. G. Freitas ${ }^{1}$, A. P. Finazzi ${ }^{2}$, F. N. Lima ${ }^{2}$, \\ H.C. Martins ${ }^{3}$, W. J. Araújo ${ }^{3}$, J. M. Borges ${ }^{3}$ \\ ${ }^{1}$ Federal University of Uberlândia (UFU), Faculty of Electrical Engineering - Uberlândia (Brazil) \\ email: loana.velasco@gmail.com, reialex@gmail.com, jcoliveira@ufu.br, lcgfreitas@yahoo.com \\ ${ }^{2}$ Federal University of Mato Grosso (UFMT), Electrical Engineering Department - Cuiabá (Brazil) \\ email:apfinazzi@cpd.ufmt.br, fernandn@terra.com.br \\ ${ }^{3}$ Companhia Energética de Minas Gerais (CEMIG) - Belo Horizonte (Brazil) \\ email: hcm@cemig.com.br, ust@cemig.com.br, jonmil@cemig.com.br
}

\begin{abstract}
The quality of electricity supply, among other issues, deals with continuity indicators as one of the most important factors for the characterization of an adequate service as far as power quality is concerned. In this context, one of the major problems responsible for the unscheduled interruptions is related to the degradation of electrical cables insulation and the well-known water tree effect emerges as an important cause for the deterioration of their insulation layer. If this phenomenon happens, a large loss of insulating properties of dielectric material used to build up such component will occur. In light of these facts, the development of procedures to evaluate, predict, and indicate the operational status of operating cables shows itself highly attractive in order to improve the quality and reliability of energy supply. Focusing on this subject, this paper presents a synthesis of existing methods and a new trend towards the mentioned matter. By using experimental measurements, carried out in medium voltage commercial operating cables in a distribution utility throughout non-invasive approach, applied voltage and insulating leakage currents are obtained to support the analysis. The data are used to obtain degradation indexes to estimate the cables physical operational conditions and the indicators found are further considered in the view of the effectiveness of the strategies for the diagnosis purposes.
\end{abstract}

\section{Keywords}

Degradation indexes, XLPE insulated cable, Leakage current, Cable diagnosis, Power quality, Water tree.

\section{Introduction}

Questions related to power quality definitely challenge engineers all over the world. Amongst these, the matter of reliable energy supply emerges as an important point towards the improvement of continuity indexes such as the duration and frequency of interruptions. In this way, the information associated with the operational conditions of equipment such as transformers, power cables, etc. has a relevant role in the behavior of the electrical system.
Among the most prominent phenomena responsible for the degradation of power cables, the water tree deterioration consists in a relatively common problem that is developed in the insulation layer of these components. Usually, it occurs when the power cable is immersed in humid environment and presents voids and impurities inside the insulation or protrusions in the semiconductor layer of a XLPE cable [1]. As water tree degradation advances, the leakage current waveform, established between inner conductor, insulation layer, and ground mesh, shows changes in both magnitude and its waveform. Such factors may evidence that the component lifetime is significantly compromised [2].

Aiming at the diagnosis of the operational conditions of an insulated cable, in terms of life expectance, several methods have been developed and employed to support decisions about the appropriateness of various actions, ranging from repairs up to replacement of this component. In particular, when seeking practical ways for determining the final effects of water tree phenomena on cable degradation and observing studies about modeling and diagnosis, several researches, like those presented in [1-9], are intended to propose procedures to detect this kind of failure through the extraction of information from performance parameters that indicate the degradation level of the insulation layer of a power cable. The methods found in the aforementioned references have different approaches to ascertain power cable status. Some examine the component in a deenergized condition while others are based on measurements carried out with an energized cable but without load. The reference [10] describes a synthesis of these strategies.

Researchers conducted and described in [10-13], complementary to the state of art of the theme, report contributions towards the establishment of mathematical 
models to represent and simulate water tree phenomena and, from sampled data, show directions to obtain performance indexes that indicate the operational state of insulated cables.

Advancing in this topic, this paper is focused in the performance assessment of procedures traditionally used to determine the state indicators of power cables. Additionally, some investigations are conducted about complementary procedures, based on the pattern of nonlinearity of leakage current waveform and related to water tree phenomena. The diagnostic work contemplates, mainly, commercial cables used in an underground energy distribution system and involves relatively new and old cables.

\section{Electrical Model of Insulated Cables with Water Tree Degradation}

The mechanism involved in the leakage current circulation in a power cable, in a path constituted by the conductor, dielectric material, and shielding connected to the ground may be, summarily, understood through Fig. 1. This figure clarifies that the conductive material itself is identified by (A) while the cable shielding, which is external to the insulation material, is indicated by (B). This outermost surface is metallic and offers protection and safety for the cable through its connection to one or more grounding points. In this way, this constructive structure provides a geometric configuration responsible for the existence of a capacitive effect, similar to those obtained by an association of two concentric cylindrical materials separated by any chemical insulator. This implies the existence of an equivalent capacitor, coming from an ideal situation, which, for practical purposes, can be further complemented by an equivalent resistance that represents the active part of leakage currents. Therefore, the equivalent circuit associated with the existence of recognized leakage currents is, ideally, presented as an arrangement of resistive and capacitive components. Figure 2 provides a cross section of the insulated cable in analysis.

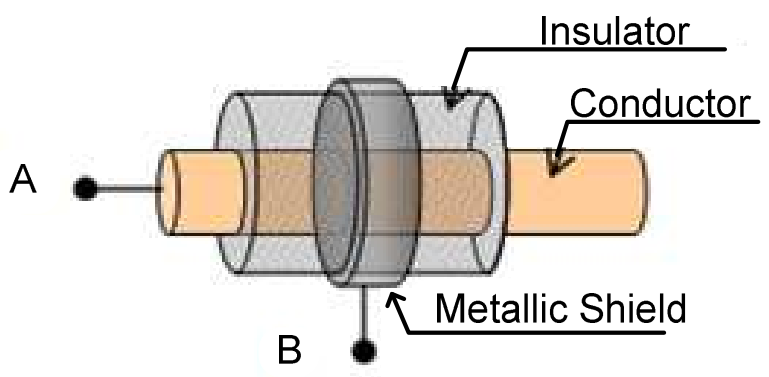

Fig. 1 - Physical design of an insulated cable

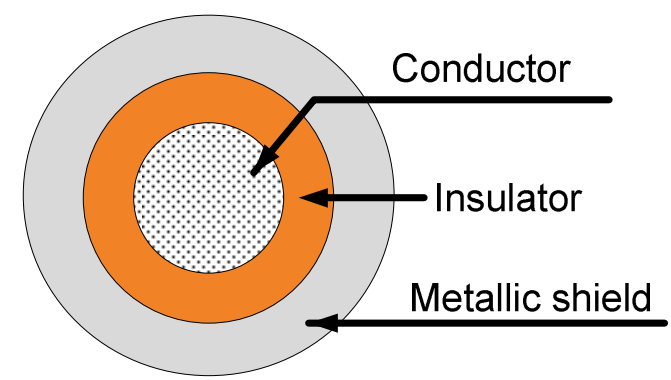

Fig. 2 - Representative cross section of an insulated cable As defined above, without the presence of anomalous effects due to natural degradation, which can appear in actual situations, the cable can be represented as an RC circuit, as shown in Fig. 3. In light of this physical design, it is evident the existence of a current established between the conductor and the shield, which is composed of two components, an active and a reactive one, where the latter is dominant in the system. For the purposes of this paper, the capacitive (reactive) component is identified by $\mathrm{i}_{\mathrm{C} 0}$ and the resistive (active) component, by $\mathrm{i}_{\mathrm{R} 0}$. The time domain representation is adopted to reproduce current and voltages across the circuit due to the need of knowing their waveforms.

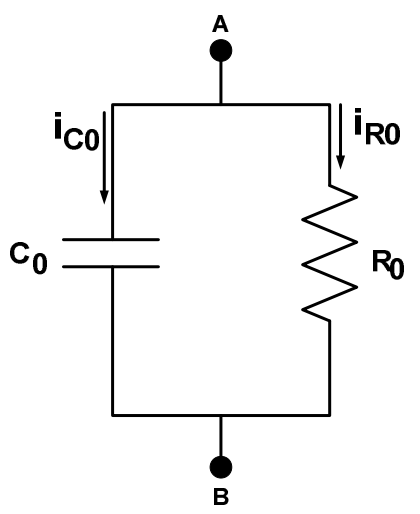

Fig. 3 - Equivalent simplified circuit for a stretch of an insulated cable without degradation.

Assuming that a specific cable presents an insulation composed by degraded and healthy portions, as symbolically shown in the Fig. 4, the electrical model to be established should consider these two situations.

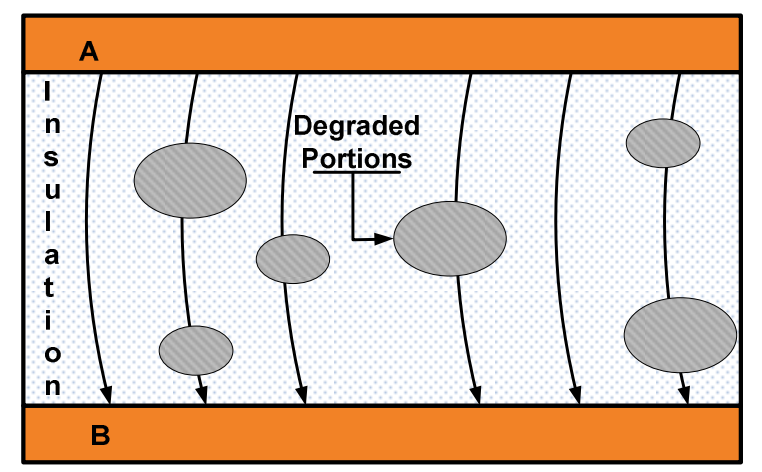

Fig. 4 - Physical interpretation of degraded areas in insulated cables.

The equivalent model to represent the non-degraded areas in the cable insulation consists of the $\mathrm{RC}$ combination aforementioned, despite the values to be assigned to these parameters, since not all the surface is 
under normal operation conditions. Regarding the portions of dielectric material that present the problems described in this paper, it must be noted that they behave with nonlinear characteristics, as mentioned in some publications on the subject [1-2]. Faced with this scenario, the adoption of linear parameters is no longer an appropriate choice to represent the degraded portions, which leads the authors towards other strategies.

For understandable reasons, the search for models that meet the requirements imposed by a non-linear relationship between voltage and current at the terminals of damaged stretch involves, necessarily, the use of devices that are compatible with such requirements, like nonlinear resistors, surge suppressors, power electronics semiconductors, etc. To illustrate this fact, Figure 5 represents the ratio of voltage versus current for a nonlinear component, which, for the purposes of this paper, could represent the region of a cable with insulation degraded. It is worth noting that the more linear part is the relationship between the quantities, and the less degraded one is the cable insulation. In this case, it should be established a relationship between the applied voltage to the cable and the corresponding leakage current.

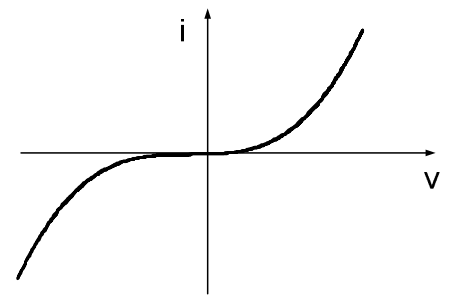

Fig.5 - V-I characteristic for the degraded portion of the insulation due to the water tree phenomenon.

In light of facts previously exposed, it is evident that the model to represent a cable stretch, which is constituted by normal and deteriorated regions, can be conceived by a combination of equivalent circuits composed of linear and nonlinear components. Therefore, Figure 6 shows the physical conception and allows noting two different and complementary circuits. The first one is destined to represent the healthy portion of the cable (multiple RC sets combined in a parallel association). The second one is composed by a series combination of a nonlinear arrangement, which includes a nonlinear resistance and is intended to represent the insulation damage, and a linear circuit, aiming to indicate the healthy regions around water tree deterioration. Naturally, the values assigned to these parameters will dictate the level of degradation involved in each situation under analysis.

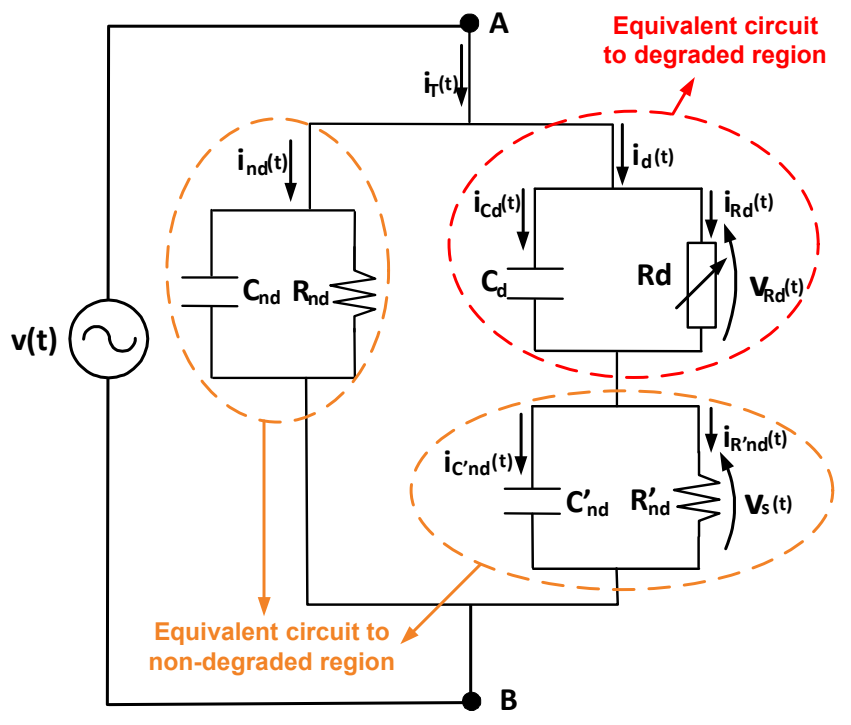

Fig.6 - Equivalent circuit which comprises healthy and degraded parts, for a given length of cable.

In Figure 6:

- $\mathrm{C}_{\mathrm{nd}}-$ Equivalent capacitance to the non-degraded cable extension;

- $\mathrm{R}_{\mathrm{nd}}$ - Equivalent resistance to the non-degraded cable extension;

- $\mathrm{C}_{\mathrm{d}}-$ Equivalent capacitance to the degraded region along the deteriorated cable insulation extension;

- $\mathrm{R}_{\mathrm{d}}-$ Equivalent resistance to the degraded region along the deteriorated cable insulation extension.

- $\mathrm{C}_{\mathrm{nd}}$ - Equivalent capacitance to the non-degraded region along the deteriorated cable insulation extension;

- $\mathrm{R}_{\mathrm{nd}}$ - Equivalent resistance to the non-degraded region along the deteriorated cable insulation extension.

\section{Performance Indexes at Estimating Degradation State of Insulated Cables}

Cables that exhibit varied degrees of degradation have, as a particular characteristic, the leakage current waveform with a third harmonic dominant effect as well as a small level of direct current [5]. Based on these assumptions, the work carried out under this research included the use of traditional degradation indexes [14] and new performance parameters, based on the nonlinear behavior of insulator degraded, as previously mentioned. The analysis procedures used are summarized in the sequence.

\section{A. Conventional Indicators}

- Dielectric power losses - The power dissipated in the dielectric $(P)$ is a state indicator that is directly associated with the degree of losses found for the cable insulation and can be used to estimate the density of deterioration [1];

- Dielectric loss factor - The dielectric loss factor $(\operatorname{tg} \delta)$ correlates the equivalent capacitive reactance of the insulation with the leakage resistance. In this way, as there is an increase of the degradation, the resistive effect 
becomes predominant, and, consequently, there will be a direct impact on this indicator.

\section{B. Non-conventional Indicators}

- Total Harmonic Distortion (THD) of leakage current - This indicator shows crescent values as the degree of cable deterioration increases [1]

- $\quad$ Third harmonic amplitude (I3) of leakage current - The magnitude of harmonic current of third order existent in the leakage current, in accordance with [5], tends to grow as the degradation level increases. This indicator behaves similarly to the Individual Harmonic Distortion (IHD), however, it presents itself as an alternative to solve the dispersion that can occur in the analysis, since the harmonic in question seems dominant;

- Third harmonic phase angle $(\theta 3)$ of leakage current - It is a state indicator that tends to the phase angle of fundamental component of leakage current as the degree of insulating deterioration enhances [1].

- $\quad$ Equivalent parameters - These indicators directly express the electrical circuit equivalent parameters, i. e., the leakage resistances and capacitances of the cable. For obvious reasons, when reducing, for example, the value of the resistance, it points to the state of the degradation of the cable;

- Linearity indicator of VxI relationship - It is an indicator that relates the instantaneous values of applied voltage to the cable and their leakage currents, obtaining, consequently, correlations that express a larger or minor linearity relation. In the context of this paper, this strategy shows itself promising for the purposes outlined here. In light of these facts, the Pearson Coefficient is used to characterize the level of non-linearity existent in the measurements, as detailed in [15]. This factor comprises a range of variation from -1 to 1 , and the higher the linearity of VxI relationship, the nearer to 1 the value of such variable. For clarity of numerical indicator, this degradation index will use a greatness that expresses the percentage difference between the measured value and the unitary reference $(\triangle \mathrm{CP} \%)$.

\section{Case Studies and Result Analysis}

The studies conducted and here reported comprise a synthesis of a large number of measurements and analysis carried out in the field and in a laboratory environment. From the different situations contemplated in the experimental tests, it was chosen to the presentation the results of measurements concerning two insulated cables, which compose an operational power supply system. The first evaluation refers to a cable stretch, called here as Sample 1, representing a XLPE insulated cable with cross section of $400 \mathrm{~mm}^{2}$, an approximated length of 145 meters and a voltage class of $8.7 / 15 \mathrm{kV}$. With respect to Sample 2, it represents another XLPE insulated cable with $400 \mathrm{~mm} 2$ of cross section, a length of approximately 60 meters and voltage class of $8.7 / 15 \mathrm{kV}$. In addition to the characteristics aforementioned for the two cables, it is noteworthy that they have a quite different usage time. This way, Sample 1 was installed less than 6 months ago, while Sample 2 is in use for over 25 years, in the local supply power system.

Using an appropriate equipment to record voltage and current, with an analysis software based in the theory previously described and in accordance with [15], Fig 7 and Fig. 8 show the waveforms extracted from the field tests concerning the leakage current and the applied voltage on the samples.

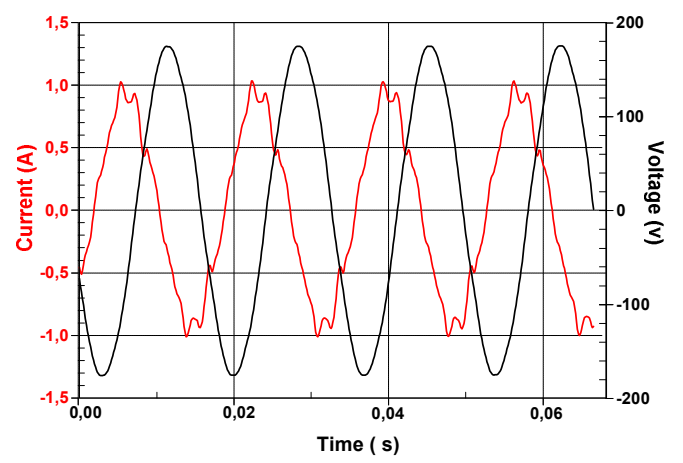

Fig. 7. - Sample 1: Applied voltage and leakage currents waveforms

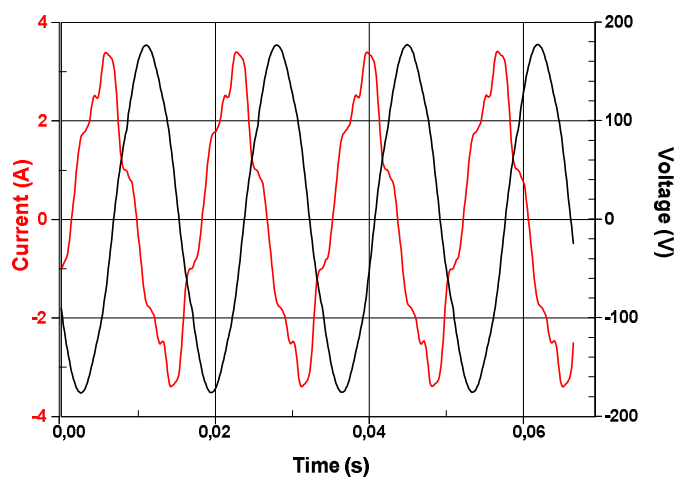

Fig. 8 - Sample 2: Applied voltage and leakage currents waveforms

From the recorded quantities and in consonance with the methodologies presented to obtain the performance indexes about the degradation state of insulated cables, the authors proceed, in sequence, to the calculations that are intended to the knowledge of representative quantities about the operational conditions of cables employed in the diagnosis process here presented. As mentioned in the previously section, it will be used the conventional and non-conventional procedures.

Figure 9 and Figure 10 show, respectively for Sample 1 and Sample 2, the relationship between the applied voltage on the cable and the leakage current, arising from field measurements. 


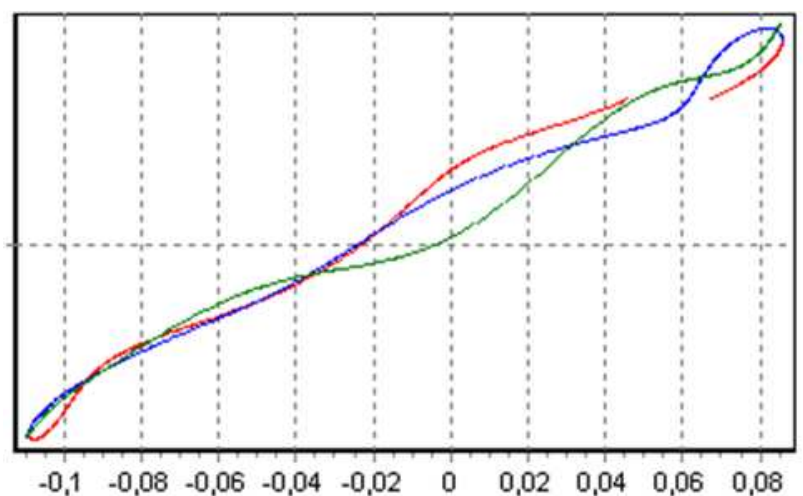

Fig. 9 - Sample 1: VxI relationship.

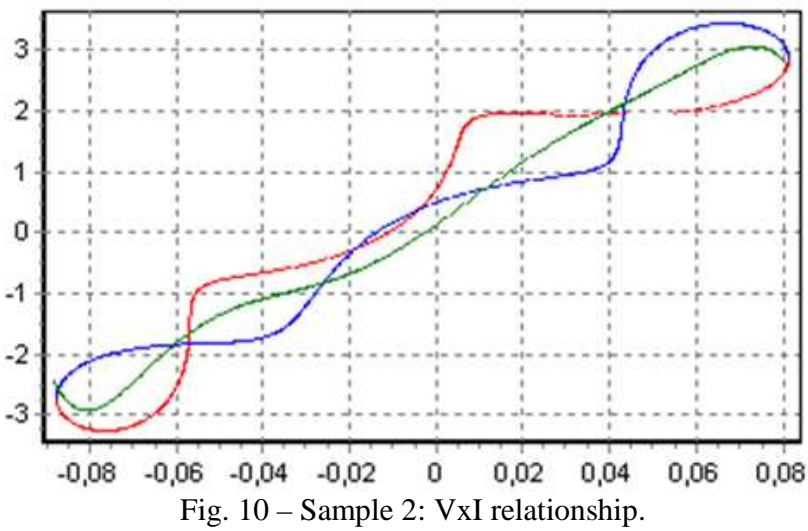

The measured data lead to results for the performance indexes, as previously established. Table 1 summarizes the main values found.

Table I - Synthesis of the results obtained

\begin{tabular}{|c|c|c|}
\hline Performance indexes & Sample 1 & Sample 2 \\
\hline $\mathrm{P}(\mathrm{W})$ & 1740,03 & 6504,38 \\
\hline Tan $\delta$ & 0,35 & 0,42 \\
\hline THDI $(\%)$ & 9,58 & 15,99 \\
\hline $\mathrm{I} 3(\%)$ & 0,0287 & 0,2362 \\
\hline$\theta 3($ degrees $)$ & 46,62 & 7,02 \\
\hline $\mathrm{R}(\mathrm{k} \Omega)$ & 31489,18 & 8227,86 \\
\hline $\mathrm{C}(\mathrm{nF})$ & 0,23 & 0,7674 \\
\hline$\Delta \mathrm{CP}(\%)$ & 1 & 5 \\
\hline
\end{tabular}

Notwithstanding the fact that the values in Table 1 express the results obtained for the different quantities used for the diagnostic studies of operational conditions of the cable samples under tests, it appears that all indicators concerning Sample 2 present values indicating a superior degradation state, when compared to Sample 1.

The indicator presented as Person Coefficient $(\triangle \mathrm{CP} \%)$ relatively to Sample 2 shows $4 \%$ of variation compared to Sample 1, implying that the non-linearity index is in accordance with the theory. However, it must be recognized, for the present moment, the lack of a database that can be used as a comparative reference, thus allowing a critical and conclusive assessment about the subject.

\section{Conclusions}

This paper has been concentrated on the establishment of theoretical fundamentals towards the diagnosis of the operational conditions of insulated cables so as to overcome unexpected electrical power interruption due to this component failure. The discussions carried out throughout the article have focused the hardwaresoftware developed equipment to perform field measurements and the analysis, as well as field results derived from real cable installations. The results selected to the presentation and discussion were quite clear at showing that measured and calculated performance indexes are promising to provide a consistent approach to indicate the insulation physical conditions. Both traditional procedures and a new way to estimate the cable degradation have been exploited and the results are shown to be in good agreement. The use of a new methodology based on the named Pearson Coefficient or Non-linearity Indicator seems to be promising. Finally, it is noteworthy that, although the results obtained are quite encouraging, the authors recognize that additional works should be conducted to consolidate the methodology intended to the estimation of the degradation state of the power cable insulation.

\section{Acknowledgment}

The authors express their gratitude to $\mathrm{CNPq}$, for the doctoral scholarship and to CEMIG for the financial support through its R\&D program (research project D368).

\section{References}

[1] A. T .Bulinski, E. So, S. S.Bamji, "Measurement of the Harmonic Distortion of the Insulation Loss Current as a Diagnostic Tool for High Voltage Cable Insulation," 07803-5935-6/00/\$10.00 (C) 2000 IEEE, pp 1615-1620, 2000.

[2] T. Furuhashi, K. Tohyama, T. Imai, Y. Murata, "Dissipation Current Waveform of Water Tree Deteriorated Low Density Polyethylene Sheet". Electrical Insulation and Dielectric Phenomena, 2006 IEEE Conference on, Oct. 15-18, pp 529-532, 2006.

[3] A. Nakajima, N. Kashiwagi, T. Murata, S. Takashi, O. Fukuda, S. Kital, K. Tokumaru, and K. Hirotau "Development of a hot-line diagnostic method for XLPE cables and the measurement results," IEEE Transactions on Power Delivery, vol.. 4, No. 2, April, pp. 857-862, 1989.

[4] S. Yamaguchi, S. Soda, N. Takada, "Development of a New Type Insulation Diagnostic Method for Hot-Line XLPE Cables", IEEE Transactions on Power Delivery, July, vol. 4 no. 3, pp. 1513-1520, 1989.

[5] T. Tsujimoto, M. Nakade, Y. Yagi, K. Adachi, H. Tanaka, Egasaki-cho, Tsurumi-ku, Yokohama, Kanagawa, Yawatakaigandori, Ichihara, Chiba, Higashi-shinagawa, Shinagawa-ku, "Development of ON-SITE Diagnostic for XLPE Cable by Harmonics in AC Loss Current," Proceedings of the 7th International Conference on Properties and Applications of Dielectric Materials, June 1-5, Nagoya, pp 73-76, 2003.

[6] T. Hashizume, C. Shinoda, T. Tani, and T. Taniguti, "A consideration on Life of XLPE cable by dry-curing process", 6th International Symposium on High Voltage Engineering, New Orleans, pp. 27-34, 1989.

[7] Wei. Zhang, Yutao Zhau, Baitun Yang, Yaonan Liu, "A Study on DC Component Method for Hot-Line XLPE Cable Diagnosis," IEEE International Symposium on 
Electrical Insulation, Pittsburgh - PA USA, June 5-8, pp 9598, 1994.

[8] T. Ozaki, N. Ito, I. Sengoku, J. Kawai, and S. Nakamura, "Changes of capacitance and dielectric dissipation factor of water-treed XLPE with voltage,", Electrical Insulating Material, 2001. (ISEIM 2001). Proceedings of 2001 International Symposium ,Himeje, Japan, pp. 459-462, 2001.

[9] Wei. Zhang, Yutao Zhau, Baitun Yang, Yaonan Liu, "A Study on DC Component Method of On-Line Diagnosis for XLPE Cables," Proceedings of the 4th International Conference on Properties and Applications Dielectrics Materials, July 3-8, Brisbane Australia,vol.1 pp 375-378, 1994.

[10] F. N. Lima, "A contribution to the insulated cable operational performance estimation due to water tree phenomenon", $\mathrm{PhD}$. Thesis - Federal University of Uberlandia - Brazil, september 2008 - in portuguese.

[11] F. N. Lima, J. C. Oliveira, D. A. Andrade, et. all, "Modeling Water Tree Phenomenon for Insulated Cable Loss Current Estimation", In: IEEE PES Transmission and Distribution Conference and Exposition: Latin America, pp. 1-6, 2008.

[12] L. N. Velasco, J. C. Oliveira, L. C. G. Freitas, A. Andrade, F.N. Lima, A.P. Finazzi "A strategy towards the degradation estimation of insulated cables throught performance indicator measurements" in Proc. of IX Induscon - 9th IEEE/IAS International Conference on Industry, November 2010

[13] L. N. Velasco, T.V. Silva, J. C. Oliveira, L. C. G. Freitas, F. P. Santilio, F.N. Lima, A.P. Finazzi, H. C. Martins, W. J. Araujo, J. M. Borges, "An Approach to Improve Power Supply Continuity throughout the Estimation of Insulated Power Cable Life Expectance Indexes" in Proc. of XI COBEP- Brazilian Conference on Power Electronics, September 2011

[14] Y. Yukihiro., T. Hideo and K. Hitoshi. "Study on Diagnostic Method for Water Treed XLPE Cable by Loss Current Measurement," 0-7803-53035-9/98/\$10.00@ 1998 IEEE, pp 653-656, 1998.

[15] S. A. Lira, "Correlation Analysis: Theoretical Approach and Construction of Coefficients with Applications", Ms.C. Dissertation, Federal University of Parana, Curitiba, 2004. 